\title{
Two Years Review of Facial Fractures at a Tertiary Care Hospital in Islamabad, Pakistan
}

\author{
Muhammad Ahmad, S. Shahid Hussain and Saleem A. Malik
}

\begin{abstract}
OBJECTIVE: To present the experience of characteristics and management of facial fractures in a tertiary care Hospital in Islamabad, Pakistan.

METHODS: Study was conducted in the department of Plastic Surgery at Pakistan Institute of Medical Sciences, Islamabad, Pakistan from January 2002 to December 2003. Only adult patients of either sex were included who presented with facial fractures. Patients below 12 years of age and those having only facial lacerations were excluded. In all cases, plain X-rays, OPG (Orthopantomogram), Water's view and CT scan (in more severe cases) were obtained. Majority of the patients was operated on routine operation days (Monday to Saturday). All other fractures were managed by Open Reduction Internal Fixation (ORIF) via intra-oral approach (gingivobuccal incision). Only those fractures were approached from the external wound when the wound lied on the line of fracture.

RESULTS: Total 133 fractures were noted in 96 patients. Most of the patients were males (76\%) with a male to female ratio of 3.1:1. Mean age of the patients was 36.5 years (range $13-79$ years). The commonest cause was road traffic accident (53.1\%) followed by assault (21.9\%). Mandible was the commonest facial bone to be involved (59.4\%).. Various associated injuries were also noted in these patients with facial lacerations $(29.9 \%)$ being the most common. Various treatment modalities were employed including Maxillo-Mandibular Fixation $(n=37)$, lag screws $(n=21)$, microplates $(n=23)$. The most frequent complication was pain and or lower lip paraesthesia.

CONCLUSION: Patients with these injuries must undergo early interventions including reduction and stabilization of fractures. Moreover, ORIF should also be undertaken wherever possible not through an external approach but the intraoral approach.
\end{abstract}

KEY WORDS: Facial fracture. Maxillofacial trauma. Open reduction and internal fixation.

\section{INTRODUCTION}

Facial trauma is so frequent that all practicing physicians see patients suffering from facial injuries at some time during their practice. ${ }^{1}$ Plastic surgeons, who have a specialized knowledge of facial anatomy, a background in aesthetics, and an expertise in wound healing are frequently consulted to treat these injuries. ${ }^{1}$ Injuries may be minimal as a small laceration or as complex as pan facial fractures. ${ }^{2}$ Thorough evaluation and management options based on sound principles should be considered and executed. ${ }^{2}$ The initial evaluation should include a complete examination which can be directed with minimal injury. Evaluation for facial injury should always begin with the integument. The underlying neuromotor function, occlusion, ocular function, and nasal passages should follow. $^{2}$ Maxillofacial injuries are common in Pakistan.
The social and economic conditions in Pakistan are different from those in the West. Few statistical studies are available concerning pattern and trends in maxillofacial trauma. In this study, we present our experience of the characteristics and management of these facial fractures in a tertiary care Hospital in Islamabad, Pakistan.

\section{PATIENTS AND METHODS}

Study was conducted in the department of Plastic Surgery at Pakistan Institute of Medical Sciences, Islamabad, Pakistan from January 2002 to December 2003. Only the adult patients of either sex were included who presented with facial fractures. Patients below 12 years of age and those having only facial lacerations were excluded. Similarly those having isolated nasal bone fractures were also not included in the study. The management started with the maintenance of air- 
way, control of breathing, antibiotic coverage and head elevation $45^{\circ}$. In patients with mandibular fractures, Barton's bandage was used to obtain the normal occlusion prior to final treatment. Regular mouth washes with liquid/semi-liquid diet were advised. In all cases, plain X-rays, e.g. OPG (Orthopantomogram) or Water's view and CT scan (in more severe cases) were obtained. Majority of the patients was operated on routine operation days (Mondays to Saturdays). The fractures were approached through intraoral route using gingivo-buccal incisions. Only those fractures were approached from the external wound when the wound lied on the line of fracture. The patients were operated under general anaesthesia using North $\mathrm{Na}-$ sal tube (Ray's tube) or local anaeshtesia using infraorbital and mental nerve blocks. Nasogastric intubation was done for $24-48$ hours in most of these patients to avoid vomiting and accidental aspiration.

\section{RESULTS}

Total 133 fractures were noted in 96 patients. Most of the patients were males (76\%) with a male to female ratio of 3.1:1. Mean age of the patients was 36.5 years (range $13-79$ years). The commonest cause was road traffic accident (53.1\%) followed by assault (21.9\%) (Table I). Mandible was the commonest facial bone involved (59.4\%) followed by maxilla (15.8\%) (Table II). Various associated injuries were also noted in these patients with facial lacerations $(29.9 \%)$ being the most common. Associated head injury was found in $11.5 \%$ of the patients (Table III). Various treatment modalities were employed including MaxilloMandibular Fixation $(n=37)$, lag screws $(n=21)$, microplates $(n=23)$ (Table IV). The most frequent complication was pain \pm lower lip paraesthesia mostly attributed to the initial injury (Table V).

TABLE I:

CAUSES OF FACIAL FRACTURES ( $n=96)$

\begin{tabular}{|l|c|c|}
\hline \multicolumn{1}{|c|}{ Cause } & $\begin{array}{c}\text { Number of } \\
\text { Patients }\end{array}$ & \% \\
\hline Road traffic accident & 51 & 53.1 \\
\hline Assault & 21 & 21.9 \\
\hline Domestic accident & 13 & 13.5 \\
\hline Industrial accidents & 6 & 6.3 \\
\hline Gunshots & 3 & 3.1 \\
\hline Sports injuries & 2 & 2.1 \\
\hline
\end{tabular}

TABLE II:

SITES INVOLVED $(n=133)$

\begin{tabular}{|l|c|c|}
\hline \multicolumn{1}{|c|}{ Site } & $\begin{array}{c}\text { Number of } \\
\text { Patients }\end{array}$ & $\%$ \\
\hline Mandible & 79 & 59.4 \\
\hline Maxilla & 21 & 15.8 \\
\hline Zygoma & 17 & 12.8 \\
\hline Temporomandibular region & 05 & 03.8 \\
\hline Frontal bone & 02 & 1.5 \\
\hline Orbit & 09 & 6.7 \\
\hline
\end{tabular}

TABLE III:

PATTERN OF ASSOCIATED INJURIES ( $n=96)$

\begin{tabular}{|l|c|c|}
\hline \multicolumn{1}{|c|}{ Injury } & $\begin{array}{c}\text { Number of } \\
\text { Patients }\end{array}$ & $\%$ \\
\hline Facial lacerations & 23 & 24 \\
\hline Limb injuries & 16 & 16.7 \\
\hline Nasal bone involvement & 13 & 13.5 \\
\hline Head injury & 11 & 11.5 \\
\hline Chest/abdomen injury & 7 & 7.3 \\
\hline Cervical injury & 2 & 2.1 \\
\hline
\end{tabular}

TABLE IV: OPERATIVE MODALITIES

\begin{tabular}{|l|l|c|}
\hline \multicolumn{2}{|c|}{ Operative modality } & Patients \\
\hline MMF & 37 \\
\hline \multirow{3}{*}{ ORIF \pm MMF } & Lag screw & 21 \\
\cline { 2 - 3 } & Microplate & 23 \\
\cline { 2 - 3 } & Dynamic compression plate & 20 \\
\cline { 2 - 3 } & Reconstruction plate & 17 \\
\cline { 2 - 3 } & Interosseous wires & 11 \\
\cline { 2 - 3 } & Mesh plate & 09 \\
\cline { 2 - 3 } & Kirschner wire & 03 \\
\hline Arch bar / Eyelets & 13 \\
\hline
\end{tabular}


TABLE V:

FREQUENCY OF COMPLICATIONS $(n=96)$

\begin{tabular}{|l|c|}
\hline \multicolumn{1}{|c|}{ Complication } & $\begin{array}{c}\text { Number of } \\
\text { Patients }\end{array}$ \\
\hline Pain & 16 \\
\hline Lower lip paraesthesia & 15 \\
\hline Palpable plate & 07 \\
\hline Malocclusion & 04 \\
\hline Infection & 02 \\
\hline Breakage of plate & 01 \\
\hline Infraorbital paraesthesia & 05 \\
\hline
\end{tabular}

FIGURE I:

PREOPERATIVE MANDIBULAR FRACTURE

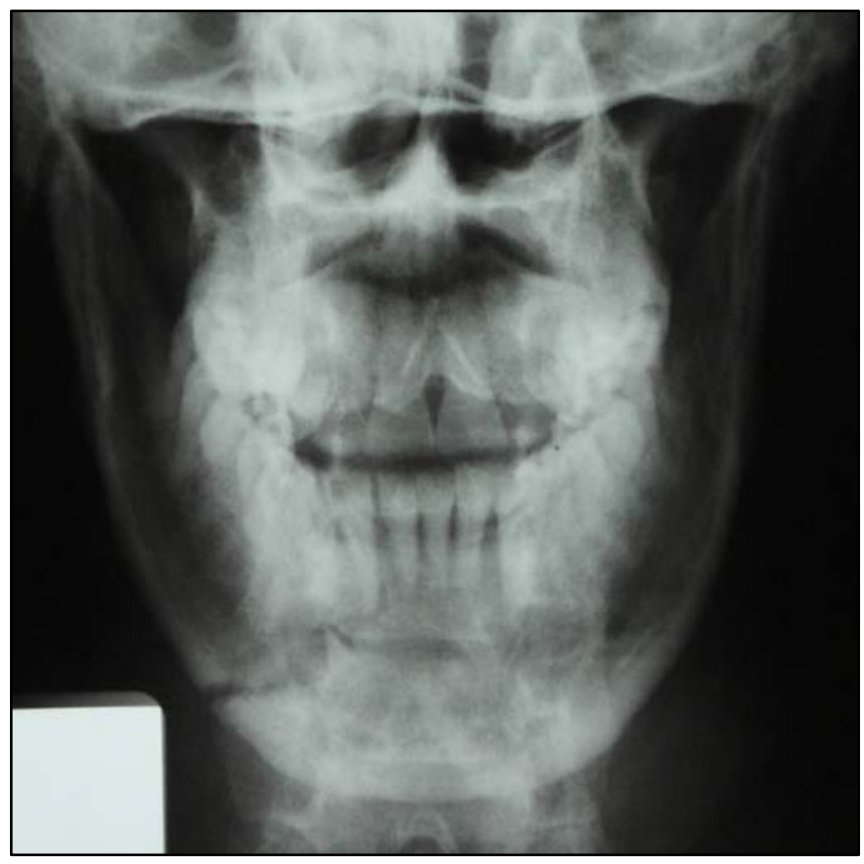

\section{DISCUSSION}

Maxillofacial trauma is presented in Accident and Emergency Department of hospital as isolated injuries or a part of polytrauma. It can be limited to superficial laceration or abrasion or it may be associated with multiple injuries to chest, head, spine, abdomen or the extremities. ${ }^{3}$ It not only hampers the function but also causes serious psychological and cosmetic deficiencies. ${ }^{4}$ Some of the most severe facial injuries are caused by automobile accidents, sports, home accidents, and missiles or gunshots. ${ }^{4}$ The frequency of facial injuries is high because face is exposed and there is little protective covering. ${ }^{3} \mathrm{~A}$ unique aspect of facial injuries is that the restoration of appearance
FIGURE II: POSTOPERATIVE MANDIBULAR FRACTURE FIXED

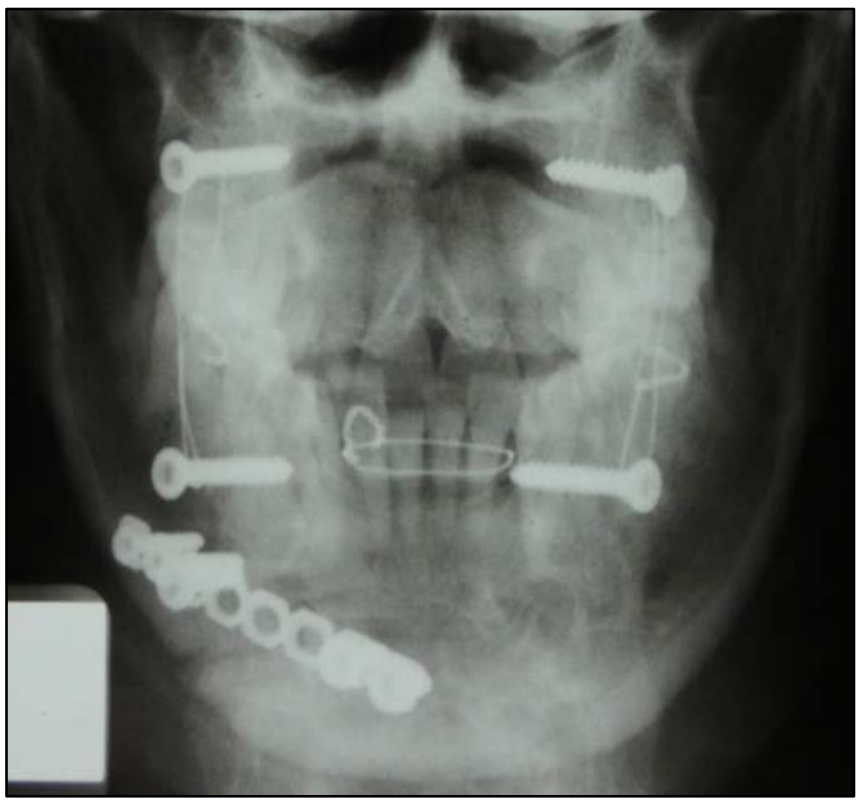

may be the chief indication for treatment. ${ }^{3}$ The restoration of appearance and function are the chief indications for the surgery. Epidemiological studies of facial trauma have classically shown that young adult males are the predominant victims. ${ }^{5-8}$ The aetiology, type and site of facial fractures vary depending on many factors. ${ }^{9}$ These injuries vary from soft tissue lacerations to complex fractures of maxillofacial skeleton. Mandible is more often fractured than the strongly supported middle third of the face because of its position,, shape and type of injury. ${ }^{6-8}$ The incidence of facial fractures varies with age, region, a period of time, climatic conditions, socio-economic differences, traffic volume, and preventive measure taken in different countries. ${ }^{10-13}$ Facial fractures are not uncommon in Pakistan. Being a male dominant society, the male works outdoors and hence are more susceptible to accidents. ${ }^{14}$ The same observation was noted in other studies. ${ }^{15-18}$ This study shows that the most common cause of facial fracture was road traffic accidents, which is consistent with the observations in other studies carried out in Pakistan ${ }^{15,17,18}$, and also in other countries. $^{5-8,19}$ But the reason for the accidents in our setup was due to the socio-economic conditions and violations of traffic rules whereas in developed countries, accidents are mostly due to alcohol intoxication. ${ }^{5}$ Majority of the patients in this study had the associated injuries which were treated concomitantly. $\mathrm{Pa}-$ tients having element of head injury were observed and treated by the active participation of the neurosurgery department. Facial lacerations were closed primarily. Intraoral approach was preferred which re- 
sulted in leaving no residual scar and improved aesthetics postoperatively. For most of the fractures, open reduction and internal fixation were used which included leg screws, dynamic compression plates, reconstruction plates, miniplates, mesh plates etc. Maxillo-Mandibular fixation (MMF) alone was used in old age patients and in patients having other concomitant injuries especially head injury, chest/abdominal injury. Majority of the fractures involving maxilla and temporomandibular region were also managed by MMF. Majority of the mandibular fractures and fractures involving orbit were managed by open reduction and internal fixation (ORIF \pm MMF). Mandible (59.4\%) was the most frequently involved in the facial fractures in the current study. Similar observations were also noted in other studies. ${ }^{5-7,15,16,18}$. Most $(86 \%)$ of mandibular fractures were managed by open reduction whereas $14 \%$ by closed reduction (MMF). Various options used were leg screws, microplates, dynamic compression plates, reconstruction plates, interosseous wires etc. Fractures of maxilla were managed by closed reduction (57\%) and open reduction (43\%) using microplates, mesh plates and reconstruction plates. The orbital fractures were fixed by using mesh plates, miniplates, interosseous wires etc._Care was taken to provide good soft tissue coverage to avoid any possibility of palpable implants postoperatively. Every effort was made to avoid any external incision. Majority (98.6\%) of the mandibular fractures were approached through intraoral incision. Only one case was approached through external wound. Similarly majority of the maxillary (88.9\%) and zygomatic fractures $(62.5 \%)$ was approached through intraoral route. However, orbital fractures were approached through the external route. Overall, $33.3 \%$ of the fractures were fixed by using external approach. Patients managed by MMF alone had a longer duration of immobilization (5-6 weeks) as compared to the patients having ORIF \pm MMF (3-4 weeks) because it resulted in early mobilization of the jaws. Moreover, we also used dental elastic rubber bands after removing the wires of MMF to encourage the mouth opening for 2-3 weeks. The complications encountered during this study were a few, majority being attributed to the initial injury. Pain $(16.7 \%)$ was the most common. Only $7.3 \%$ of the patients had malocclusion with $4.2 \%$ having slight overbite. One case of plate breakage occurred. Lower lip paraesthesia was in patients with mandibular fractures and was a result of direct injury which severed the mental nerves. Only two cases of the implant infection were noticed and in both of these patients, the fixation was done through the external wound of initial injury. No case of implant infection through intra-oral approach was found. We used the stainless steel implants instead of titanium implants which was due to the financial constrains and unavailability of titanium implants. Similarly, biodegradable/resorbable implants were also not used which have an added benefit of non-infective and these are not to be removed secondarily. ${ }^{20-21}$

\section{CONCLUSION}

Facial fractures may result in serious cosmetic and functional deformity. Patients with these injuries must undergo early interventions including reduction, stabilization of fractures as well as bone/cartilage grafting (if necessary). Moreover, ORIF should also be undertaken wherever possible not through an external approach but the intra-oral approach.

\section{REFERENCES}

1. Lettieri S. Facial trauma. In: Kolk CAV, editor. Plastic surgery, indications, operations and outcomes. St. Louis: Mosby; 2000: 923-40.

2. Hall $C D$, Eisig $S B$, Hanf $C D$. The initial management of patients with facial trauma. Cohen M, editor. Mastery of plastic and reconstructive surgery. Boston; Little, Brown and Company. 1994: 106068.

3. Manson PN. Facial fractures. In: Mathes SJ, editor. Plastic Surgery. $2^{\text {nd }}$ edition. Vol III. The head and neck, part 2. Philadelphia: Saunders Elsevier; 2006:77-380.

4. Muzaffar K. Management of maxillofacial trauma. AFID Dent J. 1998; 10:18-21.

5. Back CP, McCLean NR, Anderson PJ, David DJ. The conservative management of facial fractures: indications and outcomes. J Plast Reconstr Aesth Plast Surg 2007; 60:146-51.

6. Al- Khateeb T, Abdullah FM. Craniomaxillofacial injuries in United Arab Emeritus: a retrospective study. J Oral Maxillofac Surg. 2007; 65: 10941101.

7. Roode GJ, van Wyk PJ, Botha SJ. Mandibular fractures: an epidemiological survey at the Oral and Dental Hospital, Pretoria. SAD J. 2007; 62: 270-72.

8. Bakardjie A, Pechalova P. Maxillofacial fractures in Southern Bulgaria - a retrospective study of 1706 cases. J Cranio Maxillofac Surg. 2007; 35: 147-50.

9. Gorgu M, Adanali G, Tuneel A, Senen D, Erdogan B. Airbags and wearing seat belts prevent crush injuries or reduce severity of injury in low-speed traffic accidents. Eur J Plast Surg. 2002; 25: 21518.

10. Allan MJ, Barens MR, Bodiamala GG. The effect of seat belt legislation on injuries sustained by car occupants. Injury. 1985; 16: 471-3.

11. Shephered JP. Surgical, socio-economic and fo- 
rensic aspects of assault: a review. $\mathrm{Br} \mathrm{J}$ Oral Maxillofac Surg. 1989; 27: 89-98.

12. Perkins CS, Layton SA. The aetiology of maxillofacial injuries and the seat belt law. $\mathrm{Br} \mathrm{J}$ Oral Maxillofac Surg. 1988; 26: 353-63.

13. Simsek S, Simsek B, Abubaker AO, Laskin DM. A comparative study on mandibular fractures in United States and Turkey. Int J Oral Maxillofac Surg. 2007; 36:395-7.

14. Hussain SS, Ahmad M, Khan MI, Anwar M, Amin $M$, Ajmal S, et al. Maxillofacial trauma: current practice in management at Pakistan Institute of Medical Sciences, Islamabad. J Ayub Med Coll Abbottabad. 2003; 15: 8-11.

15. Ambreen A, Shah R. Cause of maxillofacial injuries - a three years study. J Surg Pak. 200; 6:257.

16. Zakai MA, Islam T, Memon S, Aleem A. Pattern of maxillofacial injuries received at Abbasi Shaheed Hospital, KMDC, Karachi. Ann Abbasi Shaheed Hosp. 2002; 7:291-3.

17. Abbas I, Ali K, Mirza YB. Spectrum of mandibular fractures at a tertiary care dental hospital in Lahore. J Ayub Med Coll Abbottabad. 2003; 15:12-4.

18. Khan SU, Khan M, Khan AA, Murtaza B, Maqsood A, Ibrahim W, et al. Etiology and pattern of maxillofacial injuries in the Armed Forces of Pakistan. J Coll Physicians Surg Pak. 2007; 17: 94-7.

19. Subhashraj K, Nandakumar N, Ravindran C. Review of maxillofacial injuries in Chennai, India: a study of 2748 cases. Br J Oral Maxillofac Surg. 2007; 45: 637-9.

20. Torgewrsen S, Tomer K. Maxillofacial fractures in a Norwegian district. Int $\mathrm{J}$ Oral Maxillofac Surg. 1992; 21: 335-8.

21. Yerit KC, Hainich S, Turhani D, Klug C, Witter G, Ockher $\mathrm{M}$, et al. Stability of biodegradable implants in treatment of mandibular fractures. Plast Reconstr Surg 2005; 115:1863-70.

22. Laughlin RM, Block MS, Wilk R, Maloy RB, Kent $\mathrm{JN}$. Resorbable plates for the fixation of mandibular fractures: a prospective study. J Oral Maxillofac Surg. 2007; 65: 89-96.

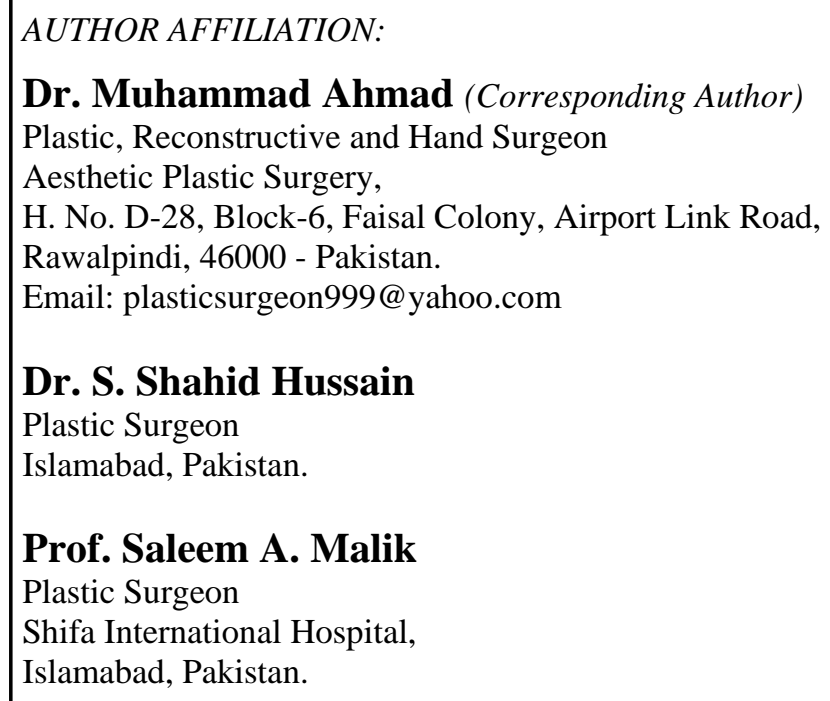

